\title{
Faktor Sosio Ekonomi yang Mempengaruhi Kepatuhan Minum Obat Antihipertensi
}

\author{
Pujiyanto*
}

\begin{abstract}
Abstrak
Hipertensi merupakan penyakit degeneratif yang banyak diderita penduduk dengan kecenderungan meningkat seiring bertambahnya umur. Dengan bertambahnya umur harapan hidup maka dimasa depan hipertensi akan menjadi masalah kesehatan yang serius. Salah satu upaya mengatasi hipertensi adalah dengan minum obat antihipertensi. Keteraturan meminum obat ditentukan oleh kepatuhan. Penelitian ini bertujuan untuk mengelaborasi pengaruh faktor sosio-ekonomi terhadap kepatuhan minum obat. Jenis penelitian adalah studi kualitatif dengan teknik wawancara mendalam. Informan adalah penderita hipertensi yang tinggal di wilayah kerja Puskesmas Beji Kota Depok, berjumlah 8 orang meliputi kategori lansia/non lansia dan laki-laki/perempuan. Wawancara dilakukan di rumah informan pada minggu pertama dan kedua Juni 2007. Rekaman wawancara dibuat transkrip dan dianalisis dengan content analysis. Hasil penelitian menunjukkan bahwa sikap patuh dan tidak patuh dalam berobat bisa muncul saling bergantian. Seluruh informan, selain mengkonsumsi obat modern, ternyata juga minum obat tradisional dari beragam tumbuhan obat dengan beragam cara membuatnya. Faktor motivasi berperan penting dalam kepatuhan minum obat. Motivasi positif memiliki efek terhadap kepatuhan minum obat yang lebih kuat dibandingkan dengan motivasi negatif. Sikap caring anggota keluarga juga berperan penting dalam kepatuhan minum obat. Berdasarkan hasil penelitian disarankan agar tenaga medis dan paramedis memotivasi anggota keluarga penderita hipertensi sebagai motivator minum obat, melakukan studi khasiat obat tradisional yang mencakup kandungan zat aktif obat dan cara pembuatan yang tepat serta efek interaksi pemakaian secara bersama-sama obat antihipertensi modern dan tradisional, dan melanjutkan program Askeskin/Jamkesmas untuk mencegah terjadinya unmet need obat antihipertensi pada orang miskin.
\end{abstract}

Kata kunci : Hipertensi, kepatuhan minum obat, obat modern, obat tradisional.

\begin{abstract}
Hypertension is a degenerative disease suffered by many people and the trends was raised as the increased of people age. In the future this disease will be a serious health problem due to the increase of life expectancy. There is an effective method to cope the hypertension by taking anti-hypertensive medicine but the regularity of its consumption depends on the compliance. The study objective was to elaborate the influence of socio-economic and cultural factors toward compliance. The research design was qualitative study and the data was gathered by indepth interview. Informen were hypertensive persons who reside in the working area of Beji Health Center, the City of Depok, consist of 8 persons including aged/non aged and male/female. The interview was conducted at the informant house on the first and second of June 2007. Then the transcript of the interview analyzed used the content analysis. Study result showed that the compliance (i.e. complied or not complied) was substitutable. All informen consumed the modern and traditional medicine simultaneously. The traditional one was made from various plants and the way he/she produced it was vary too. We discover the importance of motivation to the compliance. Positive motivation have stronger effect to the compliance as compared to the negative one. Also, family member caring was crucial to the compliance. Depends on the analyses there are some recommendation i.e. any medical and paramedical should suggest the family member of hypertensive patient to be a motivator, conducted a research to comprehend the benefit of traditional medicine including the active substance and the method of produced it effectively and the interaction effects of the use of modern and traditional antihypertensive medicine simultaneously, and to avoid the unmet need to the modern antihypertensive medicine of the poor the government should continued the health insurance program for the poor (Askeskin/Jamkesmas).
\end{abstract}

Key words : Hypertension, compliance, modern medicine, traditional medicine.

*Departemen Administrasi Kebijakan Kesehatan Fakultas Kesehatan Masyarakat Universitas Indonesia, Gd. F Lt. 1 FKM UI, Kampus Baru UI Depok 16424 (e-mail: puji_fkm@ui.edu) 
Hipertensi merupakan salah satu penyakit degeneratif yang banyak diderita penduduk di negara berkembang dan di negara maju di seluruh dunia. Hipertensi adalah suatu keadaan peningkatan tekanan darah di atas normal (tekanan darah sistolik $\geq 140 \mathrm{mmHg}$ dan tekanan darah diastolik $\geq 90 \mathrm{mmHg} .1,2$ Di Cina penderita hipertensi mencapai $36,1 \%$ dan di Amerika berjumlah sekitar 50 juta orang. ${ }^{3}$ Di Indonesia angka prevalensi hipertensi berkisar antara 27,8\%-29,39\% dan merupakan penyakit dengan frekuensi terbanyak ketujuh pada pasien rawat jalan rumah sakit.4,5 Sementara, dari laporan pelayanan Puskesmas di Kota Depok diperoleh angka kunjungan kasus hipertensi 4,2\%. Prevalensi hipertensi meningkat seiring dengan bertambahnya umur. Di Amerika hipertensi menyerang lebih dari setengah penduduk usia 6069 tahun dan sekitar tiga perempat penduduk usia $>70$ tahun. 3,5 Mengingat umur harapan hidup penduduk dunia makin panjang maka hipertensi akan menjadi salah satu masalah kesehatan yang serius dimasa depan.

Hipertensi seringkali tidak menimbulkan gejala, sementara tekanan darah yang terus menerus tinggi dalam jangka waktu lama dapat menimbulkan komplikasi. Oleh sebab itu, hipertensi perlu dideteksi dini yaitu dengan pemeriksaan tekanan darah secara berkala. Hipertensi menyebabkan meningkatnya resiko terhadap stroke, aneurisma, retinopati hipertensi (dapat menimbulkan kebutaan), gagal jantung, serangan jantung, penyakit jantung koroner (termasuk infark jantung), penyakit serebrovaskular, diabetes mellitus, penyakit ginjal kronik dan gagal ginjal terminal.1,6,7

Untuk mencegah dampak buruk hipertensi maka tekanan darah harus diturunkan. Langkah terpenting yang harus dilakukan adalah mengikuti gaya hidup sehat dan mengkonsumsi obat sesuai petunjuk dokter. ${ }^{1}$ Keteraturan meminum obat ditentukan oleh kepatuhan. Berbagai studi mengungkapkan bahwa tingkat kepatuhan minum obat pada penderita hipertensi hanya berkisar antara 50-60\%. Faktor-faktor yang berhubungan dengan kepatuhan minum obat adalah jender laki-laki, umur tua, gejala sakit dan efek samping obat. ${ }^{8,9}$ Sebagian pasien yang tidak patuh minum obat disebabkan oleh faktor ekonomi berupa ketidakmampuan membeli obat antihipertensi. ${ }^{10}$ Hambatan umum terhadap kepatuhan minum obat adalah perasaan tekanan darah sudah normal dan kealpaan. Penelitian ini bertujuan untuk mengelaborasi bagaimana pengaruh faktor sosio-ekonomi terhadap kepatuhan penderita hipertensi minum obat antihipertensi.

\section{Metode}

Jenis penelitian ini adalah studi kualitatif yang dilakukan dengan teknik wawancara mendalam pada penderita hipertensi. Informan adalah penderita hipertensi yang tinggal di wilayah kerja Puskesmas Beji Kota Depok meliputi Kelurahan Beji dan Kelurahan Beji Timur. Data calon informan diambil dari buku daftar pengunjung
Puskesmas Beji, Kota Depok dengan kasus hipertensi dan kesehatan umumnya bagus sehingga bisa diwawancarai dengan baik. Kelompok informan dipilih untuk mewakili kelompok umur (lansia dan non lansia) dan jender (lakilaki dan perempuan). Jumlah informan 8 orang, terdiri dari lansia laki-laki dan perempuan masing-masing dua orang dan non lansia laki-laki dan perempuan masingmasing 2 orang. Wawancara dilakukan di rumah penderita masing-masing pada minggu pertama dan kedua Juni 2007. Hasil rekaman wawancara dibuat transkrip dan dianalisis dengan analisis isi atau content analysis.

\section{Hasil \\ Karakteristik Informan}

Umur informan bervariasi pada kisaran 42-71 tahun dan pekerjaan informan bervariasi mulai dari guru dan pensiunan TNI hingga pembantu rumah tangga. Sebagian besar informan berasal dari suku Betawi dan hanya satu orang yang non Betawi, yakni suku Bali (Lihat Tabel 1).

\section{Lama Sakit}

Lama menderita hipertensi dari 8 informan bervariasi pada kisaran satu sampai 23 tahun, seperti terungkap dalam kutipan hasil wawancara berikut ini.

"Setahun yang lalu."

"Setelah saya mulai pensiun. Begitu saya pas pensiun itu mulai timbul gejala sakit itu, tahun 1990."

"Sudah empat tahun ini tangan dan kaki lemes saja, langsung dicek sama dokter, darah saya 250/150."

"Sudah lama juga, sejak lahir Yana (nama anak kedua, sekarang berumur 23 tahun) juga sudah ada."

\section{Gejala Sakit}

Gejala hipertensi yang dialami kedelapan informan bervariasi mulai dari tidak merasa ada gejala sama sekali hingga susah tidur dan sakit kepala di atas tengkuk. Berikut ini disampaikan beberapa kutipan wawancara.

"Enggak pa pa sih, saya enggak apa-apa. Tahu-tahu waktu berobat dibilang ibu darah tinggi 240, (sampai sekarang) enggak ada gejala."

"Sakit kepala ..... dicek ternyata darah saya naik gitu. Sakit kepala di bagian belakang di atas tengkuk. Jadi istirahat memang tidak bisa istirahat walaupun dibawa tidur enggak bisa. Kecuali dia kasih obat baru bisa beristirahat."

"Pusing-pusing, ini leher pada pegel (sambil menunjuk bagian belakang leher), kadang-kadang enggak bisa tidur, kalau malam enggak bisa tidur."

\section{Obat Modern}

Dalam pengobatan modern, semua informan menyatakan diberi obat captopril dan sebagian mendapat tambahan obat nifedipin. Pemberian resep captopril tidak hanya dari puskesmas tetapi juga ketika mereka dirujuk ke 
Pujiyanto, Faktor Sosio Ekonomi yang Mempengaruhi Kepatuhan Minum Obat Antihipertensi

Tabel 1. Karakteristik Informan

\begin{tabular}{lllll}
\hline Kel. umur & Jender & Umur & Pekerjaan & Suku \\
\hline \multirow{2}{*}{ Lansia } & Perempuan & 60 & Ibu rumah tangga & Betawi \\
& & 71 & Berdagang & Betawi \\
& Laki-laki & 65 & Pensiunan TNI & Bali \\
& & 67 & Petugas security kampung (Hansip) & Betawi \\
Non lansia & Perempuan & 42 & Ibu rumah tangga & Betawi \\
& & 47 & Pembantu rumah tangga & Betawi \\
& Laki-laki & 52 & Tukang bangunan & Betawi \\
& & 47 & Guru SD & Betawi \\
\hline
\end{tabular}

rumah sakit. Hal itu dapat disimpulkan dari kutipan wawancara berikut ini.

"Ya dikasih aja obat captopril, sampai sekarang harus itu, wajib."

"Obatnya ya cuma obat darah tinggi saja, nifedipin, captopril itu saja."

"Obat rumah sakit ya sama saja (dengan puskesmas), Captopril."

\section{Beban Finansial}

Sebagian besar informan memperoleh pengobatan gratis dari puskesmas dan rumah sakit karena menjadi peserta Askes (pegawai negeri/pensiunan) dan Askeskin (jaminan kesehatan untuk orang miskin). Informan yang bukan pegawai negeri dan tidak miskin berobat ke posyandu atau puskesmas dengan membayar retribusi sebesar dua ribu rupiah. Selain itu, tiga dari delapan informan melaporkan membeli obat captopril di apotek dengan biaya antara 150 rupiah hingga 1.000 rupiah per hari. Berikut ini disampaikan beberapa kutipan hasil wawancara mengenai biaya berobat.

"Berobatnya gratis (pakai Askes pensiunan suami). Ongkosnya enggak... yang penting saya sehat."

"Sekarang gratis (karena dapat kartu Askeskin), cuma keluar ongkos transport saja."

"Dua ribu (untuk retribusi Puskesmas Beji)."

"Saya banyakan beli sekarang (obatnya). Satu dos sepuluh lembar itu 15 ribu (rupiah), isinya 100, buat 100 hari."

"Harga satu lembar captopril (isi 10 tablet) lima ribu rupiah. Sehari (minum) dua kali. Lima ribu bisa untuk lima hari."

\section{Frekuensi Berobat}

Kutipan wawancara berikut ini menunjukkan variasi frekuensi kunjungan berobat, mulai dari jika obat habis atau ada gejala tekanan darah naik hingga yang rutin dua minggu atau satu bulan.

"Kalau obat sudah habis kita ke sana (Puskesmas Beji)."

"Kontrol kalau terasa dua hari kepala berat rasanya kiri-kanan itu berasa sakit baru saya kontrol."

"Satu bulan sekali."
"Sekarang kadang-kadang dua minggu sekali, kadang-kadang sebulan sekali, kalau lagi enak gitu."

\section{Kepatuhan Minum Obat}

Kutipan wawancara dibawah ini terungkap variasi kepatuhan informan dalam minum obat, mulai dari yang patuh, secara rutin minum obatnya, hingga yang minum obat jika tidak kelupaan saja.

"Saya minum (obat) tiap hari."

".... minum juga kalau lagi enggak lupa. Kadang kan harus disuruh minum terus."

"Rasanya kita udah perlu begitu, penting ini minum obat. Kalau dokter bilang kita sudah mesti harus (minum obat). (Kata dokternya) terus, minum obat enggak boleh pre. Dokter bilang harus tuh minum obat, entar kalau berhenti naik tinggi. Entar naik 500 bu."

".... saya minum obatnya pas lagi sakit saja saya minum, kalau pas rasa enak badan saya berhenti."

\section{Motivasi Minum Obat}

Motivasi patuh minum obat bervariasi mulai dari sekedar mengikuti nasihat dokter dan menghindari sakit hingga ingin badan sehat dan panjang umur. Simpulan itu terangkum dalam kutipan wawancara berikut ini.

"Karena kan kita dianjurin sama dokter di puskesmas.... Ibu mestinya sudah rutin minum obat..... jangan berhenti minum obat, ibu ketergantungan obat. Dia bilang begitu. Ya sudah kita jadi rutin saja (minum obat)."

"Saya takut darahnya tinggi. Ini (sambil memegang bagian belakang leher) sakit, pegel, kadang-kadang suka kenyuuut gitu."

".... saya kepengin merasakan badan terasa enak, kepala biar jangan terasa pusing, kalau berapa hari saja tidak minum obat itu sudah terasa..... beberapa kali saya ketemu dokter-dokter disarankan terus minum obatnya dirutinkan."

"Kalau ibu pengin umurnya panjang, ibu harus minum obat rutin, kata dokter gitu. Kita dimarahin gitu. Ya udah rutin jadinya minum obatnya."

\section{Ketidakpatuhan Minum Obat}

Ketidakpatuhan minum obat diantara informan, 
selain dipicu oleh karena faktor kelupaan juga disebabkan faktor subyektif merasa kondisi badannya sehat, bebas dari gejala tekanan darah tinggi. Ungkapan yang disampaikan informan tentang hal itu dapat dibaca dibawah ini.

"Kadang-kadang saya suka lupa minum (obat)."

"Anggapnya gini, ah sudah enak badannya ah malas minum obat, kata saya gitu. Entar kalau sudah parah benar, kalau sudah kagak bisa tidur, ya udah saya tidak minum obat gitu. Jadi, kayaknya agak bandel gitu. Jadi, kalau udah enak di badan, bisa tidur enak, segalagalanya makan juga gitu dilarang oleh dokter ikan asin ah bodo ah makan aja. Enak ini di badan."

\section{Obat Tradisional}

Semua informan menyatakan minum ramuan tradisional berupa rebusan atau seduhan satu atau beberapa jenis daun tumbuhan obat ini: sirih, mahkota dewa, salam, kecapi, mustajab, kumis kucing, keji beling, ceplukan, dan buah belimbing atau timun. Frekuensi minum ramuan obat tradisional ini bervariasi antara sehari satudua-tiga kali hingga seminggu sekali.

".....kalau sudah parah begini minumnya daun sirih sama daun mahkota dewa saya seduh air panas mendidih.... saya minum aja tiap hari."

"Kadang-kadang saya ada yang suruh minumin daun salam.... agak enak juga. Minum tiap hari satu gelas."

"Ada juga daun kecapi, cuma tidak berapa lama, pahit sekali itu."

"Kalau ada belimbing ya dibeliin belimbing, kalau timun memang rutin. Pagi makan satu, sore satu gitu. "

"Daun kumis kucing, daun keji beling, daun ceplukan... Tiga kali sehari segelas-segelas. Biasanya dua hari."

"Saya minumnya tidak tiap hari sih. Kadang seminggu sekali. Kadang dua hari sekali."

"Ramuan jamu-jamu dari tumbuh-tumbuhan yang pahit-pahit.... yang buahnya seperti lampion (ceplukan). Pokoknya pagi sama sore aja."

"Belimbing sayur (wuluh) digodok juga, airnya segelas jadi setengah gelas."

"Pokoknya pagi sore aja. Kalau tidak merasa pusing tidak minum."

\section{Tipologi Minum Obat Tradisional}

Terdapat dua pola pembuatan keputusan untuk minum ramuan obat tradisional, yaitu (a) jika muncul gejala tekanan darah tinggi, biasanya berupa pusing kepala, atau (b) jika kehabisan obat modern. Selain itu, ada juga dua pola dalam penggunaan obat modern selama minum ramuan obat tradisional, yakni (a) obat modern terus diminum, dan (b) penggunaan obat modern dihentikan selama minum obat tradisional.
"Kalau lagi pusing aja gitu. Kalau lagi darah tinggi gitu. Obat (modern) saya minum terus, (obat rebusan daun salam) cuma buat bantuan aja gitu."

"Kalau berasa pusing sedikit ya minum..... (obat modern) terus (diminum)."

"Kalau enggak pusing, saya enggak minum (obat tradisional)."

".... disitu kita kayak muter-muter (kepalanya), saya minum aja tuh air godok gituan, ditensi lagi 140, turun gitu.... Minum rebusan daun hanya kalau darah lagi tinggi, kalau normal tidak.”

"Jadi kalau tidak punya obat captopril, minum rebusan daun salam."

"Selama obat saya habis, saya minum saja ramuan daun-daunan."

"Kalau lupa, obatnya habis, saya minum daun-daunan. Kalau saya minum itu (ramuan daun-daunan), obat dari Puskesmas tidak saya minum, saya simpan dulu."

\section{Motivator}

Sebanyak tiga perempat informan menyatakan tidak ada orang yang memotivasi mereka untuk minum obat secara teratur. Mereka menyatakan memiliki kesadaran sendiri untuk minum obat. Sebaliknya, dua dari delapan informan menyatakan peran penting suami sebagai motivator minum obat secara teratur dengan cara mengingatkan pentingnya minum obat secara teratur dan bahkan menyiapkan obat setiap habis makan.

"Enggak, enggak ada yang mengingatkan, dari diri sendiri saja, kesadaran sendiri saja."

"Saya tidak pernah diingetin, maklum kan samasama sibuk, saya ingat sendiri saja."

"Suami ngingetin. Kata bapak gini, kalau sayang diri, katanya, minum obat teratur, ikutin anjuran dokter. Dia bilang begitu. Jadi suami ngedorong. Dokter menyuruh gitu, tambah suami, ya sudah kita pengin sehat."

"Iya, bapak tuh. Ini kalau sudah makan, bapak sudah langsung taruh obatnya. Jadi enggak pernah lupa. Dokter juga bilang ibu bagus nih.”

\section{Pembahasan}

\section{Kepatuhan Bersifat tidak Menetap}

Timbulnya hipertensi tidak selalu disertai gejala. Hal itu berdampak terhadap kepatuhan berobat penderita hipertensi. Kepatuhan berobat diukur dari frekuensi kunjungan ke fasilitas pelayanan kesehatan untuk mendapatkan obat antihipertensi dan keteraturan dalam minum obat. Dalam hal keteraturan berkunjung ke fasilitas kesehatan, hasil penelitian menunjukkan ada yang secara rutin melakukan kontrol ke fasilitas kesehatan, tetapi ada juga yang tidak teratur, hanya jika muncul gejala saja baru kontrol ke fasilitas kesehatan. Sementara, terkait dengan keteraturan minum obat ada yang dengan penuh kesadaran sendiri minum obat, meskipun tidak ada gejala sakit, sebaliknya ada yang 
baru minum obat jika merasa sakit saja.

Ternyata sikap patuh dan tidak patuh dalam berobat bisa muncul saling bergantian pada diri seorang penderita hipertensi. Di waktu tertentu seorang penderita bisa bersikap patuh terhadap rencana pengobatan dan di waktu yang lain ia bisa bersikap sebaliknya, tidak patuh. Kepatuhan yang plin-plan seperti itu biasanya terjadi pada penderita yang belum memiliki kesadaran pribadi yang kuat tentang pentingnya mematuhi aturan pengobatan sesuai yang direncanakan. Sikap plin-plan dalam mematuhi aturan pengobatan biasanya mengikuti pola timbulnya gejala sakit. Tekanan darah naik yang disertai gejala sakit membuat penderita patuh minum obat, dan sebaliknya, jika tidak ada gejala sakit penderita menjadi tidak patuh minum obat antihipertensi. Hal itu memang menjadi hambatan umum terhadap keberhasilan pengobatan hipertensi di masyarakat.

\section{Pentingnya Faktor Biaya}

Penderita hipertensi memiliki pilihan fasilitas pelayanan kesehatan untuk mendapatkan obat antihipertensi yang beragam, mulai dari klinik praktek perawat, klinik, 24 jam, puskesmas, hingga rumah sakit. Biaya berobat di fasilitas pemerintah seperti posyandu dan puskesmas hanya dua ribu rupiah per kunjungan, termasuk obat. Bahkan pegawai negeri dan pensiunan peserta Askes wajib bisa memperoleh pelayanan di puskesmas dan rujukan ke rumah sakit secara gratis. Selain itu, untuk meningkatkan akses terhadap pelayanan kesehatan bagi orang miskin pemerintah telah meluncurkan program Askeskin, melalui Peraturan Menteri Kesehatan nomor 1241 tahun 2004. Program Askeskin terbukti telah berhasil meningkatkan akses orang miskin terhadap pelayanan kesehatan. Namun, karena belum seluruh orang miskin dan tidak mampu memiliki kartu Askeskin tersebut, maka masih ada sebagian masyarakat yang tidak bisa mengakses pelayanan kesehatan, (termasuk penderita hipertensi yang menjadi informan dalam penelitian ini). Dalam situasi seperti itu, obat antihipertensi yang harganya lima ribu rupiah untuk pemakaian lima hari, atau seribu rupiah per hari, bisa menjadi beban yang cukup berat bagi rumah tangga penderita yang tidak mampu. Dalam kondisi demikian, penderita hipertensi menjadi tidak memiliki pilihan selain minum ramuan obat tradisional dari tumbuh-tumbuhan obat yang bisa mereka dapatkan dari sekitar rumahnya.

\section{Penggunaan Obat Tradisional}

Hasil penelitian menemukan bahwa semua informan penderita hipertensi selain mengkonsumsi obat modern juga minum obat tradisional dari tumbuh-tumbuhan. Uniknya, meskipun mereka berasal dari suku yang sama dan tinggal di lingkungan yang sama, ternyata ragam tumbuhan obat yang digunakan dan cara membuatnya berbeda-beda. Karena semua penderita hipertensi mengkonsumsi ramuan obat tradisional maka studi khasiat dan mudharat dari obat tradisional penting dilaksanakan agar menjadi jelas efek positif dan negatifnya.

Ada 2 aspek yang yang perlu diteliti yaitu (1) kandungan zat aktif obat dan (2) cara pembuatan yang tepat/efektif. Studi seperti itu penting karena dua alasan yaitu (a) untuk mencegah dampak buruk bagi kesehatan masyarakat jika ternyata ramuan obat tradisional semacam itu memiliki efek buruk bagi kesehatan; dan (2) untuk mempromosikan/mengkampanyekan penggunaannya jika terbukti bermanfaat dalam menurunkan tekanan darah bagi penderita hipertensi. Kampanye semacam itu akan bermanfaat dalam mengurangi ketergantungan pada obat modern yang meskipun dalam kadar yang sangat kecil, selalu memiliki efek samping yang tidak baik bagi kesehatan dan bahan bakunya masih diimpor dari negara lain. Keuntungan langsung dari pemakaian secara meluas obat tradisional yang terbukti efektif adalah (1) terjadi diversifikasi sumber bahan obat; (2) mengurangi kebutuhan devisa untuk impor bahan baku obat; (3) menciptakan kegiatan ekonomi dari produksi dan distribusi tumbuhan bahan baku obat tradisional.

\section{Obat Modern dan Tradisional Diminum Bersamaan}

Hasil penelitian menunjukkan adanya dua tipologi pemakaian obat modern dan obat tradisional. Pertama, menghentikan minum obat modern selama minum obat tradisional. Kedua, tetap minum obat modern selama minum obat tradisional. Di atas sudah dibahas masalah yang muncul pada tipe pemakaian obat modern dan obat tradisional yang pertama, yakni belum diketahuinya efek positif atau efek negatif dari pemakaian obat tradisional terhadap kesehatan pemakainya. Pada tipe pemakaian yang kedua masalahnya lebih rumit dengan ditambah belum diketahuinya efek interaksi dari pemakaian obat modern dan obat tradisional secara bersamaan. Seperti diketahui bahwa interaksi dari satu bahan obat yang terbukti efektif dengan bahan obat lainnya yang juga efektif belum tentu berdampak positif sebagaimana yang diharapkan tetapi bisa saja justru muncul dampak negatif yang tidak diharapkan. Oleh sebab itu, industri farmasi perlu didorong untuk menindaklanjutinya dengan melakukan studi efek interaksi dari pemakaian obat antihipertensi modern dan ramuan obat tradisional secara bersamaan.

\section{Pentingnya Peran Motivasi}

Telaah hasil penelitian menemukan pentingnya motivasi dalam mematuhi rencana pengobatan. Ada 3 motif yang mendorong penderita hipertensi untuk patuh minum obat yaitu (a) ingin merasakan kondisi badan yang enak atau nyaman; (b) ingin panjang umur; dan (c) ingin terhindar dari rasa sakit. Telaah lebih lanjut me- 
nunjukkan bahwa faktor motivasi agar terhindar dari rasa sakit kurang memiliki efek yang kuat dalam mendorong penderita untuk patuh minum obat. Hal itu terbukti dari sikap patuh yang plin-plan diantara penderita dengan motif menghindar dari rasa sakit. Jika ia merasa sakit akan patuh minum obat dan sebaliknya jika ia merasa sehat tidak minum obat. Sementara faktor motivasi pertama dan kedua mempunyai daya pengaruh yang kuat untuk membuat penderita yang bersangkutan mematuhi aturan minum obat yang ditentukan. Dapat disimpulkan bahwa motif yang bersifat positif (ingin badan enak/nyaman dan ingin panjang umur) lebih kuat pengaruhnya terhadap sikap patuh minum obat antihipertensi dibandingkan dengan motif negatif (menghindar dari rasa sakit).

\section{Keluarga sebagai Motivator}

Hasil penelitian menemukan bahwa anggota keluarga (suami) yang menunjukkan sikap caring kepada anggota keluarga (isteri) yang menderita hipertensi berperan penting dalam kepatuhan minum obat antihipertensi. Para informan yang diperhatikan oleh anggota keluarga, bisa berupa mengingatkan untuk minum obat atau bahkan menyiapkan obat pada waktunya, terbukti lebih patuh minum obat dibandingkan dengan informan yang anggota keluarganya tidak atau setidaknya kurang memperhatikan kebutuhan khusus yang bersangkutan untuk minum obat antihipertensi secara teratur. Oleh sebab itu, temuan ini perlu ditindaklanjuti dengan upaya dari setiap tenaga paramedis dan medis di fasilitas kesehatan untuk memberikan motivasi yang tepat, tidak saja bagi pasien tetapi juga bagi anggota keluarganya agar mau dan mampu berperan sebagai motivator bagi penderita untuk mematuhi rencana pengobatan yang telah ditentukan. Upaya seperti itu lebih bermakna dalam kasus penyakit kronis, termasuk hipertensi, yang memerlukan pengobatan jangka panjang bahkan seumur hidupnya.

\section{Kesimpulan}

Kepatuhan terhadap rencana pengobatan bisa muncul saling bergantian pada diri seorang penderita hipertensi. Motivasi berperan penting didalamnya. Motivasi positif (ingin badan enak/nyaman dan ingin panjang umur) memiliki efek terhadap kepatuhan minum obat yang lebih kuat dibandingkan dengan motivasi negatif (menghindar dari rasa sakit). Peran anggota keluarga sebagai motivator sangat penting dalam meningkatkan kepatuhan penderita minum obat antihipertensi. Selain motivasi, akses terhadap pengobatan modern yang ditentukan oleh ketersediaan dana/uang atau jaminan kesehatan juga berpengaruh terhadap kepatuhan. Jika persediaan obat antihipertensi habis biasanya penderita hipertensi minum obat tradisional sebagai penggantinya.

\section{Saran}

Untuk mengurangi unmet need obat antihipertensi khususnya pada orang miskin, maka hendaknya program Askeskin/Jamkesmas perlu dipertahankan untuk selanjutnya dilakukan percepatan pelaksanaan SJSN bagi seluruh penduduk Indonesia dengan mencakup pengobatan hipertensi dalam skema jaminan kesehatan di dalam SJSN. Untuk menjamin akses masyarakat, khususnya orang miskin, terhadap pengobatan maka program Askeskin perlu dipertahankan untuk selanjutnya dilakukan percepatan pelaksanaan SJSN bagi seluruh penduduk Indonesia. Perlu dilakukan penelitian efek farmakologis dari ramuan obat tradisional dalam pengobatan hipertensi. Selain itu, juga perlu dilakukan studi efek interaksi pemakaian secara bersama-sama obat antihipertensi modern dan obat tradisional (berupa ramuan daundaunan).

\section{Daftar Pustaka}

1. Yayasan Jantung Indonesia. Mengenal hypertensy (tekanan darah tinggi). [diakses tanggal 26 Juni 2006]. Diunduh dari: http://id.inaheart.or.id $/ ? \mathrm{p}=29$.

2. Novartis. Info kesehatan: mengenal hipertensi. [diakses tanggal 26 Juni 2006] Diunduh dari: http://id. novartis.com/kenal_tensi.shtml.

3. Jiabing, Wu. Prevalence of hypertension and the status of awareness about hypertension risk factors in the rural adult population of Anhui Province, China. Journal of National Institute of Public Health;54 (4):370-371.

4. Depkes RI. Profil kesehatan Indonesai 2003. Jakarta: Depkes RI; 2005.

5. Bastaman, Basuki dan Setianto, Budhi. Age, bodyposture, daily working load, past hypertensive drugs and risk of hypertension: A rural Indonesian study. Medical Journal of Indonesia;10 (1):29-33.

6. Markum, H.M.S.. Peran diuretik pada terapi hipertensi, khusus terapi kombinasi; dalam naskah lengkap The $4^{\text {th }}$ Jakarta Nephrology and Hypertension Course and Symposium of Hypertension. Jakarta: Perhimpunan Negrologi Indonesia; 2004.

7. Prodjosudjadi, Wiguno. Rekomendasi baru penatalaksanaan hipertensi; dalam naskah lengkap The $4^{\text {th }}$ Jakarta Nephrology and Hypertension Course and Symposium of Hypertension. Jakarta: Perhimpunan Negrologi Indonesia; 2004.

8. Almas A, Hameed A, Hameed B, Islam M. Compliance to antihypertensive therapy, J Coll Physicians Surg Pak. 2006;16(1):23-6. [diakses 7 Maret 2007]. Diunduh dari: http://www.ncbi.nlm.nih.gov/ entrez/query.fcgi?tool=abstarctplus\&db.

9. Khalil SA, Elzubier AG, Drug compliance among hypertensive patients in Tabuk, Saydi Arabia, J Hypertens. 1997 ;15(5):561-5. [diakses tanggal 7 Maret 2007]. Diunduh dari: http://www.ncbi.nlm.nih.gov/entrez/ query.fcgi? tool=abstarctplus\&db.

10. Elzubier AG, Husain AA, Suleiman IA, Hamid za. Drug compliance among hypertensive patients in Kassala, eastern Sudan, East Mediterr Health J. 2000;6(1):100-5. [diakses tanggal 7 Maret 2007]. Diunduh dari: http://www.ncbi.nlm.nih.gov/entrez/query.fcgi?tool=abstarctplus\&db. 